\title{
Systemic Scleroderma in Childhood: A Case Report
}

\author{
Aslı ASLAN, Güldane KOTUROĞLU, Betül SÖZERİ, Zafer KURUGÖL \\ Department of Pediatrics, Medical Faculty of Ege University, İzmir, Turkey
}

\begin{abstract}
Juvenile systemic scleroderma is a rare chronic multi-system connective tissue disease in childhood. Although rare in children, it is an important cause of morbidity and mortality. Juvenile systemic scleroderma is one of the most severe rheumatologic conditions diagnosed in children. In this article, we report a six-year-old boy diagnosed with scleroderma.

Keywords: Childhood; juvenile systemic sclerosis; scleroderma.
\end{abstract}

Scleroderma is derived from the Greek words skleros (hard or indurated), and derma (skin). ${ }^{1}$ Hippocrates first described this condition as thickened skin. ${ }^{1}$ Juvenile systemic sclerosis (JSSc) is a rare chronic multi-system connective tissue disease characterized by symmetrical thickening and hardening of the skin, associated with fibrous changes in internal organs, as well as vascular and immune system abnormalities in children aged 16 years or younger. ${ }^{2}$ Although rare, JSSc is among major causes of morbidity and occasional mortality. ${ }^{3}$ Besides, it is one of the most severe rheumatologic conditions diagnosed in children. ${ }^{3}$ In this article, we report a rare scleroderma case in a pediatric patient.

\section{CASE REPORT}

A six-year-old male patient, who presented with stiff hands and difficulty in lifting his fingers, was admitted to our clinic. His medical history was non-specific without any prior complaints. His current symptoms first appeared one and a half months ago with stiff finger tips spreading over to the toes two or three days before admission. No inquiry for prior history for medicine intake or being subject to toxic agents was taken.

Physical examination revealed that he was in the $10-25^{\text {th }}$ percentile for weight, and $50-75^{\text {th }}$ percentile for height, with a pulse rate of $90 \mathrm{bpm}$ and blood pressure of $90 / 60 \mathrm{mmHg}$. The stiffness at the palms and fingers in both hands were confirmed. His lips were tense, and he had difficulty in opening his mouth. Other examination results were non-specific.

Hematological examination and blood biochemistry results were normal. Urin analysis result was also normal without proteinuria. The rheumatoid factor was negative; the viral serologic testing for anti-hepatitis A virus, immunoglobulin $\mathrm{M}$, and immunoglobulin $\mathrm{G}$ were negative, anti-hepatitis $\mathrm{B}$ was positive (530.06 $\mathrm{mIU} / \mathrm{mL}$ ), anti-hepatitis $\mathrm{C}$ virus was negative, group agglutination and Rose Bengal tests were negative, Epstein-Barr virus was negative, anti-cytomegalovirus immunoglobulin $M$ was negative, anti-cytomegalovirus immunoglobulin $\mathrm{G}$ was positive, and parvovirus was negative.

The antinuclear antibodies (ANA) indicated to scleroderma with $1 / 320$ positive thin granularity.

Received: May 16, 2013 Accepted: August 02, 2013

Correspondence: Aslı Aslan, M.D. Ege Üniversitesi Tıp Fakültesi Çocuk Sağlığı ve Hastalıkları Anabilim Dalı, 35040 Bornova, İzmir, Turkey.

Tel: +90 232 - 3901427 e-mail: asli.aslan@ege.edu.tr

O2014 Turkish League Against Rheumatism. All rights reserved. 


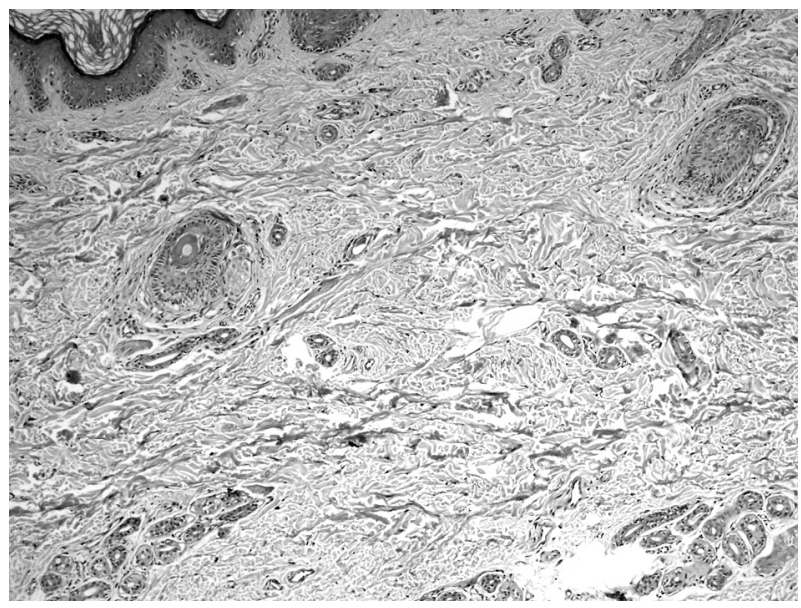

Figure 1. Connective tissue proliferation below the level of sweat gland (H-E x 200).

Proximal interphalangeal joint flexion contraction was examined bilaterally in both hands. Magnetic resonance imaging of the hands showed an inflammation of the flexor and extensor tendon. Dermal biopsy demonstrated increased connective tissues under the sweat glands, which was consistent with the symptoms of scleroderma (Figure 1). Electrocardiographic and echocardiographic results were unremarkable. No ocular uveitis was detected. The patient did not have difficulty in swallowing liquid or solid food without retrosternal burn, stomachache, diarrhea, or constipation. Esophagography and gastroesophageal reflux scintigraphy, respiratory function test, and highresolution computed tomography results were also normal. No pathology was detected in the abdominal ultrasonography.

The patient was diagnosed with JSSc due to the sclerotic involvement at the finger level. Initially, the subject was administered $20 \mathrm{~g}(1 \mathrm{~g} / \mathrm{kg})$ intravenous immunoglobulin only once over 12 hours and methylprednisolone $30 \mathrm{mg} / \mathrm{kg}$ every other day was initiated. The treatment was sustained with weekly methotrexate and oral methylprednisolone. The patient was also enrolled to a physical exercise program. The patient was in remission by the fourth year of follow-up.

\section{DISCUSSION}

The presentation can be gradual with accumulation of the symptoms over weeks to months. Early symptoms may be non-specific such as unexplained fever, fatigue, or loss of appetite. In addition, patients may suffer from prolonged fever, oral ulcers, Raynaud's phenomenon, skin rash, photosensitivity, alopecia, pleuropericarditis, glomerulonephritis, arthritis, unexplained abdominal pain, muscle weakness, sicca symptoms, and many constitutional symptoms such as anorexia, muscle ache, fatigue, and weight loss. ${ }^{1-3}$

Juvenile systemic sclerosis is a rare connective tissue disease. The etiology of JSSc is unknown. It is the one of the most important rheumatic diseases in childhood. Fibrosis of the skin, subcutaneous tissues, and internal organs are some of the characteristic outcomes. Therefore, early detection of the severity of the disease may play a significant role in establishing the most effective therapeutic regimen. ${ }^{1-3}$

In all sclerodermic subjects, while $10 \%$ shows the disease symptoms before the age of 20 , only 1 to $2 \%$ shows the symptoms before the age of 10 . The mean age of onset is 8.1 years, and the peak age is between 10 and 16 years. ${ }^{4,5}$ In our patient, the symptoms started at the age of six.

Skin biopsies from patients with scleroderma show various histologic features. Characteristics are particularly evident in the dermal microvasculature, including endothelial swelling and concentric thickening of the vascular basement membrane. ${ }^{6}$

The proposed criteria for the classification of JSSc include one major criterion [sclerosis and/or skin induration specific for systemic sclerosis (SSc)], and eight minor criteria reflecting the relevant involved organ systems (e.g. pulmonary, cardiac, gastrointestinal, renal, vascular, musculoskeletal, neurological, and serological involvement). ${ }^{7}$ The Raynaud's phenomenon and pulmonary hypertension, in particular, and renal crisis caused by fibrotic arteriosclerotic changes may be observed due to vascular involvement. ${ }^{8}$

Multiple organ involvement in children at the time of diagnosis may be less common than in adults. The majority of children with JSSc presents with skin changes (tightening, thinning, atrophy) of the hands and face, and/or the Raynaud's phenomenon. A multicenter retrospective study of 153 children with JSSc revealed that the Raynaud's 
phenomenon was the most frequent symptom in these patients (75\%). Other involvements of the skin can be less frequent such as sclerodactyly, edema, and calcinosis. ${ }^{8}$ Difficulty in opening the mouth, tightness and slimness on the lip skin may be seen. Similarly, our patient suffered from skin flattening, slimness, color change with sclerodactyly and difficulty in opening his mouth, and tight lip skin. Microvascular changes may occur distinctively at nail beds. ${ }^{4}$ A further research revealed that our patient had also Raynaud's phenomenon, which was supported by the capillary reduction at his nail beds.

The most frequent involvement followed by the sclerodermal skin symptoms and the Raynaud's phenomenon can be the gastrointestinal system. All gastrointestinal locations from the mouth to the anus can be involved, the esophageal dysmotility being the most common. ${ }^{8-11}$ Radiological findings may show abnormalities in the absence of any symptoms, even. ${ }^{12}$

Renal involvement can be detected by proteinuria, hematuria, or progressive renal failure. The reported prevalence of renal crisis in children with JSSc ranges from 0.7 to $4 \% .{ }^{4,5}$ In a case series of 153 children with SSc, about $10 \%$ had renal involvement, but there was only one child with acute renal crisis, accelerated hypertension and renal failure. ${ }^{5}$ However, our subject's kidney functions and creatinine clearance values were normal.

Although uncommon, cardiac involvement can be a significant cause of morbidity among children with JSSc. The major cardiac complications include pericarditis with effusion, constrictive pericardium, arrhythmias, and congestive heart failure. Heart failure may develop due to pulmonary hypertension or secondary cor pulmonale, or diffuse fibrous replacement of cardiac muscles. In addition, pulmonary hypertension caused by pulmonary vascular disease can lead to myocardial damage and right heart failure. ${ }^{8,12,13}$ Our subject's cardiac investigation findings were unremarkable.

Pulmonary involvement, although frequently asymptomatic until dyspnea appears, may present with a dry, hacking cough.4.5 Unlike adults, interstitial pulmonary fibrosis, a devastating complication, has been rarely reported in children with JSSc. Pulmonary involvement considerably increases the morbidity and mortality rates of scleroderma. ${ }^{8}$ High-resolution computed tomography can be the most effective method for detecting any lung involvement. 8,9,11,14 In our case, high-resolution computed tomography scan of the lungs was normal.

Furthermore, ANA are highly prevalent in patients with JSSc (81\%) and 34\% of the patients were anti-topoisomerase I (anti-Scl-70) antibodies positive. However, there may be no correlation between the disease activity and ANA positivity. In addition, rheumatoid factors may be present in $16 \%$ of children with localized scleroderma. ${ }^{15}$ Antitopoisomerase I antibodies may be less frequent in children (20-30\%) compared to adults (30-40\%), as anticentromere antibodies, which can be detected in $7-8 \%$ of children. ${ }^{5,6,16}$ Antibodies may also help differentiate the disease from other connective tissue disorders. ${ }^{17}$ Similarly, our patient had ANA-positive with $1 / 320$ thin granularity and anti-Scl-70 negative. As a differential diagnosis, the systemic lupus erythematosus (SLE) and other collagen tissue diseases were disregarded in our patient with anti-DNA, and anti-Ro/SSA and la/ SSB antibodies-negative.

Arthralgia and myalgia are among the earliest symptoms of scleroderma with musculoskeletal involvement. ${ }^{11}$ Typically, arthralgia and morning stiffness can be seen, which can be misdiagnosed as a rheumatologic disease. ${ }^{8}$ Similarly, our patient reported painless finger stiffness in both hands which vanished during the course of the day.

Being exposed to some medicines and chemical substances such as bleomycin, isoniazid pentazocine, sodium valproate, bromocriptine, trichlorethylene, vinyl chloride, nitrofurantoin, and hydantoin etc. may also cause sclerodermal skin changes. However, our patient had no history of such exposure or disease.

Juvenile systemic sclerosis involves the skin, muscle, and visceral organs; therefore, the differential diagnosis should include other multiple-system organ diseases with skin involvement including juvenile dermatomyositis, mixed connective tissue disease, SLE, juvenile idiopathic arthritis, overlap syndrome, eosinophilic fasciitis, chronic graft versus host disease, nephrogenic systemic fibrosis, phenylketonuria with sclerodermatous skin lesions, and syndromes of premature aging. ${ }^{16-19}$ 
Our patient had none of the clinical symptoms, which are common in childhood onset SLE, including malar rash, ulcers, renal involvement, proteinuria, urinary cellular casts, seizures, thrombocytopenia, hemolytic anemia, fever, and lymphadenopathy. He also had no symmetrical or proximal muscle weakness, elevated skeletal muscle enzyme levels or cutaneous involvement with eruption on exposed surfaces, pruritus or subcutaneous calcification. Therefore, polymyositis or dermatomyositis were excluded. In addition, he did not suffer from arthritis until the past six weeks before diagnosis or arthralgia during the day. Thus the diagnosis of juvenile idiopathic arthritis was excluded.

In childhood, localized scleroderma may recover spontaneously. Different therapeutic approaches should be employed in the active inflammatory stage and the following irreversible stage with fibrosis. ${ }^{4}$ The prognosis of SSc in children appears to be better than in adults. Martini et al. ${ }^{20}$ observed that fibrosis on chest X-rays, raised creatinine levels and pericarditis are strongly and independently predictive of death, and there is a short interval between the disease onsets.

To the best of our knowledge, no drug has been reported yet, which can be significantly beneficial in the management of JSSc. Also, basic healthcare quality measures for children with chronic diseases are extremely important, since JSSc can adversely affect nutrition, school attendance, and capacity of exercise. Recently, the European League against Rheumatism and the Scleroderma Trials and Research group have acknowledged the need for evidence-based recommendations for clinicians to be used in clinical practice. There is a lack of mortality data of disease modifying agents for SSc. Nevertheless, current treatments, although less than optimal, are still worthwhile. ${ }^{21}$ For instance, Two randomized clinical trials have shown that methotrexate improves skin score in early diffuse SSc. ${ }^{22,23}$ However, positive effects on other organ manifestations have not been established yet. Methotrexate may be considered for the treatment of skin manifestations of early diffuse SSc. ${ }^{21}$ Our patient's skin manifestations resolved with methotrexate therapy at 2.5 years.

Systemic sclerosis-related digital vasculopathy such as the Raynaud's phenomenon and digital ulcers are among the universal manifestations of
SSc. Patients with SSc demonstrated an increased platelet activation and aggregation. ${ }^{24}$ There is a good theoretical rationale for antiplatelet therapy, at least in SSc-related Raynaud's phenomenon. However, only small-scale clinical trials were performed on this subject, which did not show any definite benefit. ${ }^{25}$ Also, calcium antagonists and prostanoids reduced the frequency and severity of SSc-related Raynaud's phenomenon attacks. ${ }^{21}$ Our patient did not have severe vasculopathy and responded to aspirin.

Anti-inflammatory, vitamin-D analogs and ultraviolet treatment models can be used in localized scleroderma. Early treatment initiation is crucial to achieve the maximum clinical benefit and avoid any irreversible fibrotic tissue damage. ${ }^{9,26,27}$

Management approaches which can be appropriate for pediatric patients should be chosen considering any possible adverse effects of the medications (i.e., corticosteroid-induced growth failure and osteoporosis) as well as the psychosocial impact of the chronicity and physical deformity for both the child and his/her parents. Having no vital organ involvement and being diagnosed at an early stage, our patient was subcutaneously administered methotrexate $20 \mathrm{mg} /$ week and low-dose steroid following intravenous immunoglobulin and pulse methylprednisolone.

In conclusion, SSc shows insignificant symptoms in children aged $<10$ years. We present our case due to the rare occurrence of systemic scleroderma in children, indicating that it is a collagen tissue disease with the possibility of acquiring good results with early treatment.

\section{Declaration of conflicting interests}

The authors declared no conflicts of interest with respect to the authorship and/or publication of this article.

\section{Funding}

The authors received no financial support for the research and/or authorship of this article.

\section{REFERENCES}

1. David M. A case of scleroderma mentioned by Hippocrates in his aphorisms. Korot 1981;8:61-3. 
2. Rodnan GP. When is scleroderma not scleroderma? The differential diagnosis of progressive systemic sclerosis. Bull Rheum Dis 1981;31:7-10.

3. Preliminary criteria for the classification of systemic sclerosis (scleroderma). Subcommittee for scleroderma criteria of the American Rheumatism Association Diagnostic and Therapeutic Criteria Committee. Arthritis Rheum 1980;23:581-90.

4. Scalapino K, Arkachaisri T, Lucas M, Fertig N, Helfrich DJ, Londino AV Jr, et al. Childhood onset systemic sclerosis: classification, clinical and serologic features, and survival in comparison with adult onset disease. J Rheumatol 2006;33:1004-13.

5. Martini G, Foeldvari I, Russo R, Cuttica R, Eberhard A, Ravelli A, et al. Systemic sclerosis in childhood: clinical and immunologic features of 153 patients in an international database. Arthritis Rheum 2006;54:3971-8.

6. Fleischmajer R, Perlish JS, Reeves JR. Cellular infiltrates in scleroderma skin. Arthritis Rheum 1977;20:975-84.

7. Zulian F, Woo P, Athreya B et al. Preliminary classification criteria for systemic sclerosis in children. Clin Exp Rheumatol 2005;23:S43.

8. Pope JE. Musculoskeletal involvement in scleroderma. Rheum Dis Clin North Am 2003;29:391-408.

9. Derk CT, Rasheed M, Spiegel JR, Jimenez SA. Increased incidence of carcinoma of the tongue in patients with systemic sclerosis. J Rheumatol 2005;32:637-41.

10. Hsu VM, Moreyra AE, Wilson AC, Shinnar M, Shindler DM, Wilson JE, et al. Assessment of pulmonary arterial hypertension in patients with systemic sclerosis: comparison of noninvasive tests with results of right-heart catheterization. J Rheumatol 2008;35:458-65.

11. Nietert PJ, Sutherland SE, Silver RM, Pandey JP, Knapp RG, Hoel DG, et al. Is occupational organic solvent exposure a risk factor for scleroderma? Arthritis Rheum 1998;41:1111-8.

12. Lo CY, Shyur SD, Chu SH, Huang LH, Kao YH, Lei WT, et al. Juvenile scleroderma: experience in one institution. Asian Pac J Allergy Immunol 2010;28:279-86.

13. Quartier P, Bonnet D, Fournet JC, Bodemer C, Acar P, Ouachée-Chardin $\mathrm{M}$, et al. Severe cardiac involvement in children with systemic sclerosis and myositis. J Rheumatol 2002;29:1767-73.

14. Derk CT, Rasheed M, Artlett CM, Jimenez SA. A cohort study of cancer incidence in systemic sclerosis. J Rheumatol 2006;33:1113-6.

15. Galan A, Cowper SE, Bucala R. Nephrogenic systemic fibrosis (nephrogenic fibrosing dermopathy). Curr Opin Rheumatol 2006;18:614-7.
16. Coşkun T, Ozalp I, Kale G, Göğüș S. Scleroderma-like skin lesions in two patients with phenylketonuria. Eur J Pediatr 1990;150:109-10.

17. Reveille JD, Solomon DH; American College of Rheumatology Ad Hoc Committee of Immunologic Testing Guidelines. Evidence-based guidelines for the use of immunologic tests: anticentromere, Scl-70, and nucleolar antibodies. Arthritis Rheum 2003;49:399-412.

18. Jansen T, Romiti R. Progeria infantum (HutchinsonGilford syndrome) associated with sclerodermalike lesions and acro-osteolysis: a case report and brief review of the literature. Pediatr Dermatol 2000;17:282-5.

19. Epstein CJ, Martin GM, Schultz AL, Motulsky AG. Werner's syndrome a review of its symptomatology, natural history, pathologic features, genetics and relationship to the natural aging process. Medicine (Baltimore) 1966;45:177-221.

20. Martini G, Vittadello F, Kasapçopur O, Magni Manzoni S, Corona F, Duarte-Salazar C, et al. Factors affecting survival in juvenile systemic sclerosis. Rheumatology (Oxford) 2009;48:119-22.

21. Kowal-Bielecka O, Landewé R, Avouac J, Chwiesko S, Miniati I, Czirjak L, et al. EULAR recommendations for the treatment of systemic sclerosis: a report from the EULAR Scleroderma Trials and Research group (EUSTAR). Ann Rheum Dis 2009;68:620-8.

22. van den Hoogen FH, Boerbooms AM, Swaak AJ, Rasker JJ, van Lier HJ, van de Putte LB. Comparison of methotrexate with placebo in the treatment of systemic sclerosis: a 24 week randomized double-blind trial, followed by a 24 week observational trial. Br J Rheumatol 1996;35:364-72.

23. Pope JE, Bellamy N, Seibold JR, Baron M, Ellman $\mathrm{M}$, Carette S, et al. A randomized, controlled trial of methotrexate versus placebo in early diffuse scleroderma. Arthritis Rheum 2001;44:1351-8.

24. Postlethwaite AE, Chiang TM. Platelet contributions to the pathogenesis of systemic sclerosis. Curr Opin Rheumatol 2007;19:574-9.

25. Beckett VL, Conn DL, Fuster V, Osmundson PJ, Strong CG, Chao EY, et al. Trial of platelet-inhibiting drug in scleroderma. Doubleblind study with dipyridamole and aspirin. Arthritis Rheum 1984;27:1137-43.

26. Perera A, Fertig N, Lucas M, Rodriguez-Reyna TS, Hu P, Steen VD, Medsger TA Jr. Clinical subsets, skin thickness progression rate, and serum antibody levels in systemic sclerosis patients with anti-topoisomerase I antibody. Arthritis Rheum 2007;56:2740-6.

27. Arnett FC. Is scleroderma an autoantibody mediated disease? Curr Opin Rheumatol 2006;18:579-81. 